\title{
Magnetic properties and microwave absorption properties of short carbon fibres coated by $\mathrm{Ni}-\mathrm{Fe}$ alloy coatings
}

\author{
YING LIU ${ }^{1}$ and CHENGWEN QIANG ${ }^{2, *}$ \\ ${ }^{1}$ College of Materials Science and Engineering, Taiyuan University of Technology, Taiyuan 030024, China \\ ${ }^{2}$ Institute of Modern Physics, Chinese Academy of Science, Lanzhou 730000, China
}

MS received 13 May 2015; accepted 11 August 2015

\begin{abstract}
Ni-Fe alloy coatings were successfully prepared on carbon fibre (CF) surfaces by means of electroplating at $25^{\circ} \mathrm{C}$ for $560 \mathrm{~s}$. The structures and morphologies of the composite were characterized using X-ray diffraction and scanning electron microscopy. The coercivity $\left(H_{c}\right)$ and saturation magnetization $\left(H_{\mathrm{s}}\right)$ of the $\mathrm{Fe}_{0.45} \mathrm{Ni}_{0.55} / \mathrm{CF}$ composites were $45.19 \mathrm{Oe}$ and 1513.59 emu $\mathrm{g}^{-1}$, respectively. The reflectivity of $\mathrm{Fe}_{0.45} \mathrm{Ni}_{0.55} / \mathrm{CF}$ composites was less than $-5 \mathrm{~dB}$ over the range of 1.1-5.4 GHz. The reflectivity of $\mathrm{Fe}_{0.45} \mathrm{Ni}_{0.55} / \mathrm{CF}$ composites was less than $-10 \mathrm{~dB}$ over the range of 1.6-2.1 GHz. The lowest reflectivity of the $\mathrm{Fe}_{0.45} \mathrm{Ni}_{0.55} / \mathrm{CF}$ composites was $-14.7 \mathrm{~dB}$ at $2.0 \mathrm{GHz}$ and the corresponding thickness was $3.3 \mathrm{~mm}$.
\end{abstract}

Keywords. Ni-Fe alloy films; carbon fibre; electrodeposition; microwave absorbing materials.

\section{Introduction}

Microwave absorption materials have attracted a lot of attention in recent years because of their potential application in wireless data communication, local area networks, satellite television and heating systems. ${ }^{1}$ In particular, magnetic materials and carbon fibres have received steadily growing interest as microwave absorbing and shielding materials in the high-frequency range owing to their fascinating properties. ${ }^{2,3}$ However, conventional microwave absorption materials, such as magnetic metal and ferrite, are very heavy which restricts their applications in many fields. One of the ways to solve the problem is to couple the magnetic absorption materials with low density substrates. Carbon fibres (CFs) are suitable substrate materials owing to their low density, high strength and excellent electrical property. ${ }^{4,5}$ However, CFs do not show magnetic loss for microwave, which limits its application in this field. Therefore, many treatments have been used to enhance the absorbing property of $\mathrm{CFs}$, including changing the cross-sectional shape and size of $\mathrm{CFs},{ }^{6-8}$ as well as modifying the $\mathrm{CF}$ surface such as coating the surface with a layer of metal or other oxide. ${ }^{6-10} \mathrm{Com}$ posites of $\mathrm{CFs}$ and magnetic materials not only have lighter weight but also possess good conductivity and strength.

For example, films of Ni-Fe binary alloy are used for recording, memory and storage devices. ${ }^{11,12}$ The most common film growth processes such as sputtering, molecular beam epitaxy require high or ultrahigh vacuum. It is also possible to prepare such ferromagnetic films by electroplating, which

\footnotetext{
*Author for correspondence (qiangchw04@163.com)
}

does not need any vacuum system. Moreover, it has more advantages like low cost and easy control by changing the electrodeposition parameters in the experiment. Quantities of metallic coatings were prepared by the electroplating method, such as $\mathrm{Ni}-\mathrm{Co},{ }^{13} \mathrm{Cu}-\mathrm{Sn},{ }^{14} \mathrm{Zn}-\mathrm{Co}^{15}$ and $\mathrm{Zn}-$ $\mathrm{Ni},{ }^{16}$ composite films of $\mathrm{Ni}-\mathrm{SiC}^{17}$ and $\mathrm{Fe}-\mathrm{Cr}-\mathrm{P}^{18}$ were also prepared by the electroplating method.

Additionally, in recent time reports, the reflectivity of $\mathrm{Fe}_{3} \mathrm{O}_{4} / \mathrm{CF}$ composites is less than $-20 \mathrm{~dB}$ over the range of 5.49-7.75 GHz (4.10-5.12 $\mathrm{mm}$ in thickness). The lowest reflectivity of the $\mathrm{Fe}_{3} \mathrm{O}_{4} / \mathrm{CFs}$ composites is $-35 \mathrm{~dB}$ at $6.37 \mathrm{GHz}$ and the corresponding thickness is $4.41 \mathrm{~mm} .{ }^{2} \mathrm{CuO} / \mathrm{CF}$ and $\mathrm{CuO} / \mathrm{Co} / \mathrm{CF}$ composites exhibited strong electromagnetic wave absorption, the strongest reflection loss (RL) of the composites reaches maxima of $-29.6 \mathrm{~dB}$ at $7.9 \mathrm{GHz}$ and $-42.7 \mathrm{~dB}$ at $10.8 \mathrm{GHz}$, respectively.

Chemical plating and reducing are usually adopted to prepare magnetic coatings on CFs. ${ }^{19}$ The drawbacks of these methods are time consuming, low yield and of uncertain quality. Electroplating has been used to make $\mathrm{CFs}$ with $\mathrm{Ni},{ }^{20}$ $\mathrm{Cu},{ }^{21} \mathrm{Fe}^{22}$ etc. However, to the best of our knowledge, there is little worth reported on magnetic alloy-coated CFs from electrodeposition, while this method offered a simple and efficient way to the fabrication of microwave absorbing material with excellent magnetic properties. The properties of $\mathrm{Fe}-$ Ni films are seriously affected by their compositions and structures, ${ }^{23}$ thus a reliable control of the composition and structure is an important issue in designing the magnetic functionality of these materials.

In this paper, a conventional electroplating method was employed to prepare CFs coated with magnetic $\mathrm{Ni}-\mathrm{Fe}$ alloy. The magnetic and microwave absorption properties of the $\mathrm{Ni}-\mathrm{Fe} / \mathrm{CF}$ composites were investigated. 


\section{Experimental}

CFs with 3000 filaments were selected. The diameter of a single filament was in the range of 5-10 $\mu \mathrm{m}$. The pretreatment involved two steps: (1) the CFs were immersed in acetone for $2 \mathrm{~h}$ and then washed with distilled water and (2) the $\mathrm{CFs}$ were treated with nitric acid $\left[\mathrm{HNO}_{3}\right]$ for $5 \mathrm{~h}$ and then washed with distilled water. The electroplating of $\mathrm{Ni}-\mathrm{Fe}$ alloy was performed in a conventional three-electrode cell, employing an electrochemical workstation with a potential range -12 to $12 \mathrm{~V}$, current range -2 to $2 \mathrm{~A}$. The reference electrode was a saturated calomel electrode. Firstly, Ni-Fe films with different $\mathrm{Ni}$ contents and morphologies were successfully electrodeposited on ITO glass (indium tin oxide, surface resistance is less than $20 \Omega$ ) from the electrolytes containing both different $\mathrm{Ni}^{2+}$ and $\mathrm{Fe}^{2+}$ concentrations and different $\mathrm{pH}$ values without stirring. The result shows that the saturation magnetization of the $\mathrm{Ni}-\mathrm{Fe}$ alloy films reaches a maximum value and coercivity $\left(H_{\mathbf{c}}\right)$ reaches a minimum value at $\mathrm{Ni}: \mathrm{Fe}=0.55: 0.45 . M_{\mathrm{s}}$ reaches a maximum value at $\mathrm{pH}=2.9 .^{24}$ Finally, the composition of electrolytes are shown in table 1 , together with major plating parameters. After electroplating, the CFs coated with $\mathrm{Ni}-\mathrm{Fe}$ alloy was dried in the air at room temperature. By changing the molar ratio $\mathrm{Ni}^{2+} / \mathrm{Fe}^{2+}$ in the reaction electrolyte from $0.50 / 0.50$ to $0.90 / 0.10$, the Ni context $x$ in the films ranges from 38 to $84 \% . \mathrm{Ni}: \mathrm{Fe}=0.55: 0.45$ and $\mathrm{Ni}: \mathrm{Fe}=0.69: 0.21$ was selected for our experiment sample.

The structure and morphology of the Ni-Fe/CF composites were characterized using X-ray diffraction (XRD) and a field-emission scanning electron microscope (SEM). XRD measurements were performed on a Rigaku D/Max-2400 $\mathrm{X}$-ray diffractometer using $\mathrm{Cu}-\mathrm{K} \alpha$ radiation $(40 \mathrm{kV}, 60 \mathrm{~mA})$ from $25^{\circ}$ to $90^{\circ}$ with a step width of $0.02^{\circ}$ and a counting time of $3 \mathrm{~s}$ per step. The morphology and thickness of the $\mathrm{Ni}-\mathrm{Fe} / \mathrm{CF}$ composites were analysed on a Hitachi S-4800 field-emission SEM operated at an accelerating voltage of $5 \mathrm{kV}$. The magnetic properties of the $\mathrm{Ni}-\mathrm{Fe} / \mathrm{CF}$ composites were measured with a Lake Shore 7304 vibrating sample magnetometer (VSM) at room temperature. An Agilent

Table 1. Constitution and operating conditions of the plating bath.

\begin{tabular}{ll}
\hline Reagents & Concentration \\
\hline $\mathrm{FeSO}_{4} \cdot 7 \mathrm{H}_{2} \mathrm{O}$ & $0.10-0.02 \mathrm{M} \mathrm{dm}^{-3}$ \\
$\mathrm{NiSO}_{4} \cdot 7 \mathrm{H}_{2} \mathrm{O}$ & $0.10-0.18 \mathrm{M} \mathrm{dm}^{-3}$ \\
$\mathrm{H}_{3} \mathrm{BO}_{3}$ & $0.40 \mathrm{M} \mathrm{dm}^{-3}$ \\
Ascorbic acid & $1.70 \mathrm{mM} \mathrm{dm}^{-3}$ \\
Thiourea & $1.38 \mathrm{mM} \mathrm{dm}^{-3}$ \\
Temperature & Room temp. \\
pH values & 2.9 \\
Current density & $0.5 \mathrm{~A} \mathrm{dm}$ \\
Plating duration & $560 \mathrm{~s}$ \\
Anode & Iron plate \\
Cathode & Carbon fibres \\
\hline
\end{tabular}

E8363B PNA vector network analyzer was used to measure the microwave absorption coefficient of $\mathrm{Ni}-\mathrm{Fe} / \mathrm{CF}$ composites. The $\mathrm{Ni}-\mathrm{Fe} / \mathrm{CF}$ composites were cut into $2-3 \mathrm{~mm}$ in length, and then homogeneously dispersed into paraffin via a ultrasonic method and pressed into a ring (external diameter of $7 \mathrm{~mm}$ and internal diameter of $3 \mathrm{~mm}$ ) at $350 \mathrm{MPa}$. The weight fraction of the Ni-Fe/CF composites was $50 \%$.

The RL of a microwave absorption layer backed by a perfect conductor was calculated by the following equations

$$
\begin{aligned}
& \operatorname{RL}(\mathrm{dB})=20 \log _{10}\left|\frac{Z_{\text {in }}-1}{Z_{\text {in }}+1}\right|, \\
& Z_{\text {in }}=\left(\frac{\mu_{\mathrm{r}}}{\varepsilon_{\mathrm{r}}}\right)^{1 / 2} \tan \mathrm{h}\left[\mathrm{j}\left(\frac{2 \pi f d}{c}\right)\left(\mu_{\mathrm{r}} \varepsilon_{\mathrm{r}}\right)^{1 / 2}\right],
\end{aligned}
$$


Figure 1. XRD pattern of the $\mathrm{Ni}-\mathrm{Fe} / \mathrm{CF}$ composites (a) and the XRD patterns of the $\mathrm{Fe}_{1-x} \mathrm{Ni}_{x}$ films with the Ni contents of $x=$ $0.38,0.55,0.63,0.69$ and 0.84 . The inset shows the magnified (110) diffraction peaks of the XRD patterns (b). 
where $\mathrm{RL}$ is the ratio of reflected power to incident power in dB. $Z_{\text {in }}$ the input impedance of absorber, $d$ the thickness of the absorber, and $c$ and $f$ the velocity of light and the frequency of microwave, respectively. $\varepsilon_{\mathrm{r}}=\varepsilon^{\prime}-\mathrm{j} \varepsilon^{\prime \prime}$ and $\mu_{\mathrm{r}}=$ $\mu^{\prime}-\mathrm{j} \mu^{\prime \prime}$ are the complex permittivity and complex permeability of the absorber material, respectively. ${ }^{2}$ According to equations (1) and (2) when RL is -5 and $-10 \mathrm{~dB}$, the attenuation of microwave absorption materials achieves 68 and $90 \%$, respectively.

\section{Result and discussion}

\subsection{Structure and morphology of $\mathrm{Ni}-\mathrm{Fe} / \mathrm{CF}$ composites}

XRD pattern of the prepared $\mathrm{Ni}-\mathrm{Fe} / \mathrm{CF}$ composites was measured and is shown in figure $1 \mathrm{a}$. The results show that $\mathrm{Ni}-\mathrm{Fe}$ phases are clearly found in the products. The diffraction peaks between $10^{\circ}$ and $30^{\circ}(2 \theta)$ are from the CF substrate. The three diffraction peaks of the Ni-Fe can be indexed as the (110), (200) and (211) diffraction planes of cubic structure.
The diffraction peaks of C (205) and C (516) can also be seen in the XRD pattern. The three diffraction peaks located at about $45.6^{\circ}, 64.9^{\circ}$ and $82.3^{\circ}$ are corresponding to $\mathrm{FeNi}$ (110), FeNi (200) and FeNi (211) of cubic structure. As shown in figure $1 \mathrm{~b}$, the diffraction peaks of FeNi (110) show stronger preferred orientation than that of FeNi (211) and FeNi (200) at any Ni content $x$. From the inset in figure 2, it can be seen that the diffraction peaks in the XRD patterns shift slightly towards low angles with the increasing $\mathrm{Ni}$ contents $x$, indicating increasing lattice constant with the increase in Ni contents $x$. This can be attributed to the large atom radius of $\mathrm{Ni}(0.162 \mathrm{~nm})$ as compared with the atom radius of $\mathrm{Fe}(0.110 \mathrm{~nm})$. The incorporation of large atoms into the lattice of the film would expand the lattice and increase the lattice parameters. ${ }^{24,25}$ In the deposition of $\mathrm{Ni}-\mathrm{Fe}$ alloy by electroplating with the same sulphate concentration, the product of $\mathrm{Ni}-\mathrm{Fe}$ is a result of anomalous $\mathrm{Ni}$ deposition. ${ }^{24}$ Owing to the low solubility of carbon in iron and nickel, Ni-Fe alloy is deposited on CF by mechanical bonding, and chemical reactions do not take place at the interface between the alloy and CF.
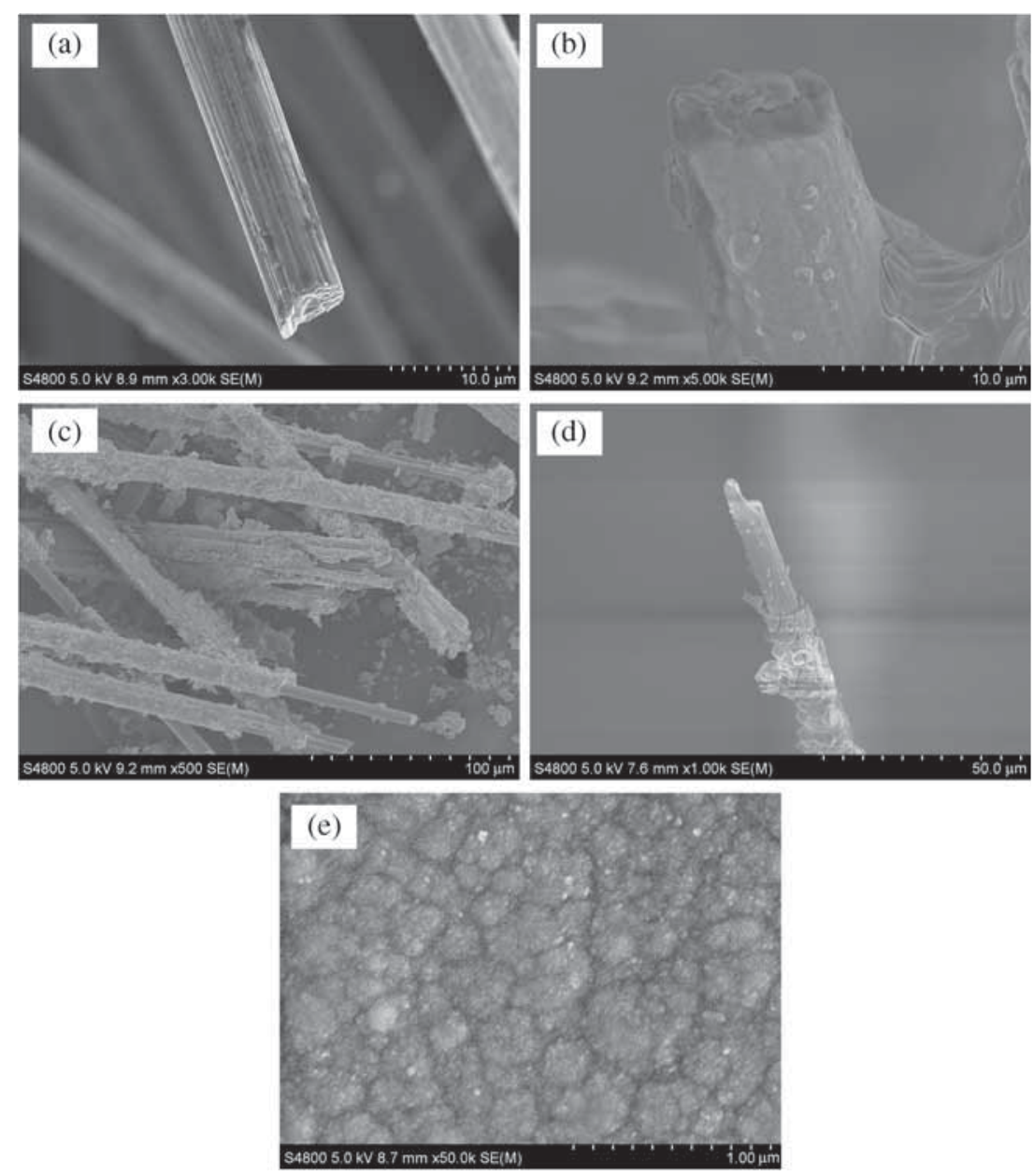

Figure 2. Low- and high-magnification $\mathrm{SEM}$ images of the $\mathrm{Fe}_{0.45} \mathrm{Ni}_{0.55} / \mathrm{CF}$ composites: (a) an untreated $\mathrm{CF}$, (c) $\mathrm{Fe}_{0.45} \mathrm{Ni}_{0.55} / \mathrm{CF}$, (b and d) a single $\mathrm{Fe}_{0.45} \mathrm{Ni}_{0.55} / \mathrm{CF}$ and (e) $\mathrm{Fe}_{0.45} \mathrm{Ni}_{0.55}$ coatings. 
The surface morphology of the Ni-Fe/CF composites is shown in figure 2. Figure 2a displays an SEM image of the untreated CFs. It can be seen that the diameter of the CFs is about $5 \mu \mathrm{m}$. The results show that all CFs are completely coated with Ni-Fe alloy. The coatings on most of the CFs are dense and uniform (figure 2c). High-magnification SEM images of $\mathrm{Ni}-\mathrm{Fe} / \mathrm{CF}$ composites are shown in figure $2 \mathrm{~b}$ and $\mathrm{d}$. As can be seen from the surface morphology, the CFs are completely covered by Ni-Fe alloy coatings and the thickness of the FeCo alloy coatings is about $2 \mu \mathrm{m}$ (figure 2d). Figure 2e displays the surface morphologies of $\mathrm{Ni}_{0.55} \mathrm{Fe}_{0.45}$ deposition on the ITO glass. The surface of the $\mathrm{Ni}_{0.55} \mathrm{Fe}_{0.45}$ coatings is more similar with a single $\mathrm{Ni}-\mathrm{Fe} / \mathrm{CF}$ (figure $2 \mathrm{~b}$ ).

\subsection{The properties of $\mathrm{Ni}-\mathrm{Fe} / \mathrm{CF}$ composites}

The magnetic properties of the $\mathrm{Ni}-\mathrm{Fe} / \mathrm{CF}$ composites were measured using VSM at room temperature. Figure 3a shows that $M_{\mathrm{S}}$ increases with the Ni content $x$ increasing from 0.38 to 0.84 , reaches a maximum value of $2498.88 \mathrm{emu} \mathrm{cm}^{-3}$ at $x=0.84$. Meanwhile, $H_{\mathrm{c}}$ decreases with the Ni content $x$ increasing from 0.38 to 0.55 , reaches a minimum value of 43.14 Oe at $x=0.55$, and then increases with the further
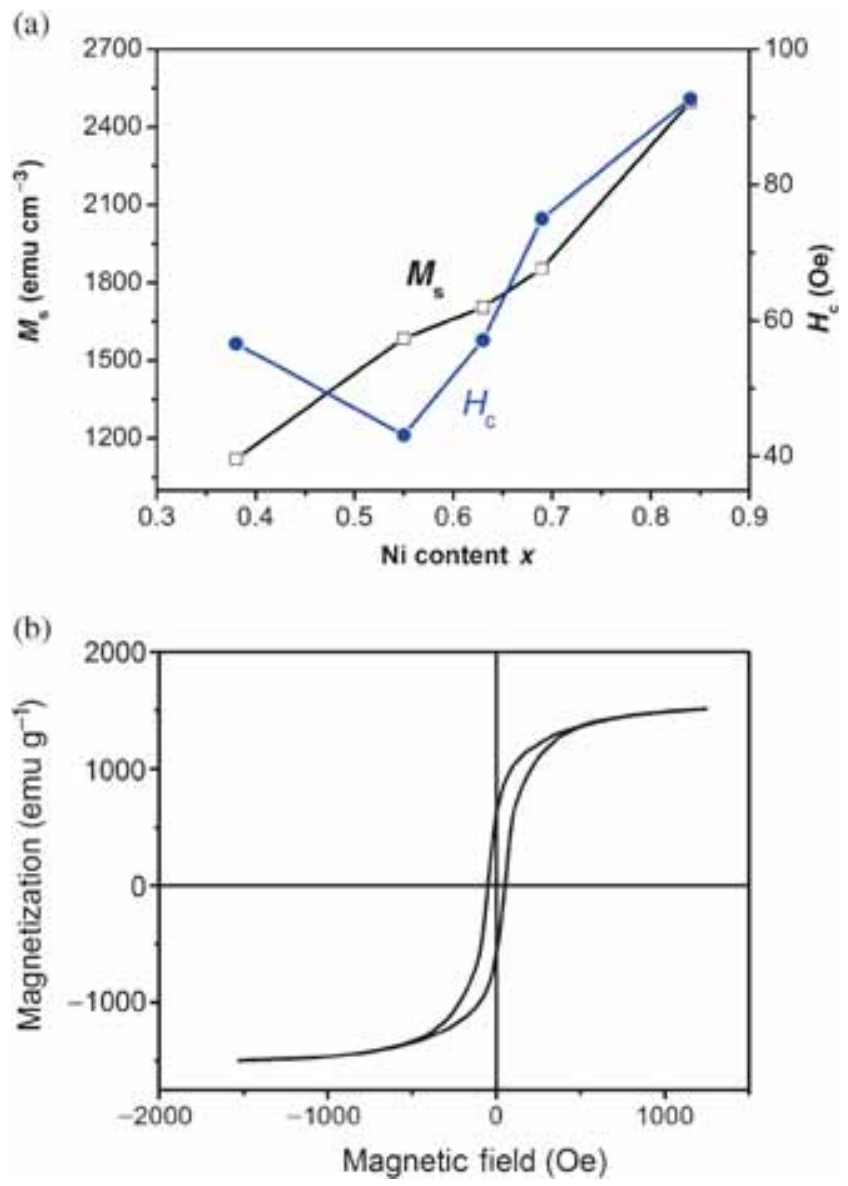

Figure 3. (a) Dependence of saturation magnetization $\left(M_{\mathrm{S}}\right)$ and coercivity $\left(H_{\mathrm{c}}\right)$ of the $\mathrm{Fe}_{1-x} \mathrm{Ni}_{x}$ films on the Ni content $x$ and $(\mathbf{b})$ magnetic hysteretic loop of $\mathrm{Fe}_{0.45} \mathrm{Ni}_{0.55} / \mathrm{CF}$ material. increase in $x$. The change of the magnetic properties of the $\mathrm{Fe}-\mathrm{Ni}$ films can be attributed to the increase in $\mathrm{Ni}$ content in the deposited films. Figure $3 \mathrm{~b}$ shows the magnetic hysteresis loop of the $\mathrm{Fe}_{0.45} \mathrm{Ni}_{0.55} / \mathrm{CF}$ composites. Zeng et al reported that the $\mathrm{CFs}$ exhibited paramagnetism. ${ }^{7,8}$ Figure 3 shows that the saturation magnetization of the $\mathrm{Fe}_{0.45} \mathrm{Ni}_{0.55} /$ $\mathrm{CF}$ composites is reached rapidly and the coercivity $\left(H_{\mathrm{c}}\right)$ and saturation magnetization $\left(H_{\mathrm{s}}\right)$ are 45.19 Oe and $1513.19 \mathrm{emu} \mathrm{g}^{-1}$.

It is known that the microwave absorption mechanism of the absorption materials can be explained by dielectric loss and magnetic loss. In order to investigate the intrinsic reasons for microwave absorption properties, the four parameters $\left(\varepsilon^{\prime}, \varepsilon^{\prime \prime}, \mu^{\prime}, \mu^{\prime \prime}\right)$ of the $\mathrm{Ni}-\mathrm{Fe} / \mathrm{CF}$ composites were directly measured using the coaxial line method in the $0-18 \mathrm{GHz}$ range. As shown in figure $4 \mathrm{a}$, with fluctuation during the increase in frequency, the real $\left(\varepsilon^{\prime}\right)$ part of the complex permittivity declines from 35.7 to 12.8 while the imaginary $\left(\varepsilon^{\prime \prime}\right)$ part increases from 2.0 to 13.5. The dielectric behaviours of the $\mathrm{Fe}_{0.21} \mathrm{Ni}_{0.69} / \mathrm{CF}$ coatings have same character due to $\mathrm{CF}$ only possess good conductivity. Figure $4 \mathrm{~b}$ shows the real $\left(\mu^{\prime}\right)$ and imaginary $\left(\mu^{\prime \prime}\right)$ of complex permeability observed as a function of frequency. It can be seen that the former is between 0.6 and 1.8; the latter is between 0.3 and 0.9. The real $\left(\mu^{\prime}\right)$ and imaginary $\left(\mu^{\prime \prime}\right)$ of complex permeability of the $\mathrm{Fe}_{0.21} \mathrm{Ni}_{0.69} / \mathrm{CF}$ coatings have much more differentials with the $\mathrm{Fe}_{0.45} \mathrm{Ni}_{55} / \mathrm{CF}$ coatings as shown in figure 4c. The low $\mu^{\prime}$ and $\mu^{\prime \prime}$ values can be related to the smaller magnetization of the $\mathrm{Ni}-\mathrm{Fe} / \mathrm{CF}$ as compared with that of pure $\mathrm{Ni}-\mathrm{Fe}$ alloy. $^{24}$

On the basis of the above discussion, the microwave attenuation of the $\mathrm{Ni}-\mathrm{Fe} / \mathrm{CF}$ composites is mainly caused by dielectric loss in this work. The microwave absorption frequency is independent of composition due to the dielectric loss of the Ni-Fe/CF composites attributed to CFs.

Figure 5 shows the frequency dependence of the reflectivity of different thickness of the $\mathrm{Fe}_{0.45} \mathrm{Ni}_{0.55} / \mathrm{CF}$ composites. It can be found that the absorption frequency and absorption bandwidth (the width of absorption frequency range under the same reflectivity) of the $\mathrm{Fe}_{0.45} \mathrm{Ni}_{0.55} / \mathrm{CF}$ decrease with the increase in thickness. When the microwave is incident on an absorber sample backed by a perfect conductor, the relation between the matching frequency $f$ and the matching thickness is expressed by $f=n c / 4 d(|\varepsilon||\mu|)^{1 / 2}(n=1,3,5,7$, 9...). So in figure 5a with increasing thickness, the values of RL shifts to low frequency can easily be turned by adjusting the thickness of the composites. It can also be seen that the lowest reflectivity of the $\mathrm{Fe}_{0.45} \mathrm{Ni}_{0.55} / \mathrm{CF}$ composites is -14.7 $\mathrm{dB}$ at $2.0 \mathrm{GHz}$ and the corresponding thickness is $3.3 \mathrm{~mm}$. Additionally, when the reflectivity is $-5 \mathrm{~dB}$, the reflection loss of the microwave absorption materials achieves $68 \% .^{6,7}$ The results show that the reflectivity of $\mathrm{Fe}_{0.45} \mathrm{Ni}_{0.55} / \mathrm{CF}$ composites is less than $-5 \mathrm{~dB}$ over the range of 1.1-5.4 GHz. When the reflectivity is less than $-10 \mathrm{~dB}$ the reflection loss of microwave absorption materials achieves $90 \%$. The reflectivity of $\mathrm{Fe}_{0.45} \mathrm{Ni}_{0.55} / \mathrm{CF}$ composites is less than $-10 \mathrm{~dB}$ over the range of 1.6-2.1 GHz. The experimented results 
(a)

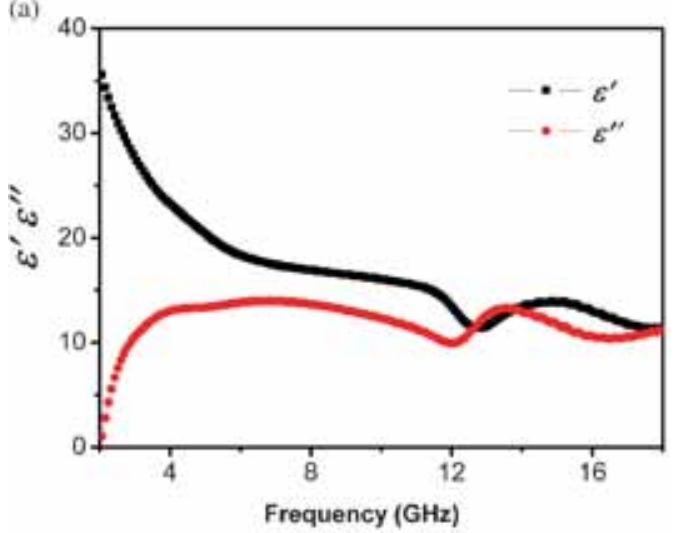

(b)

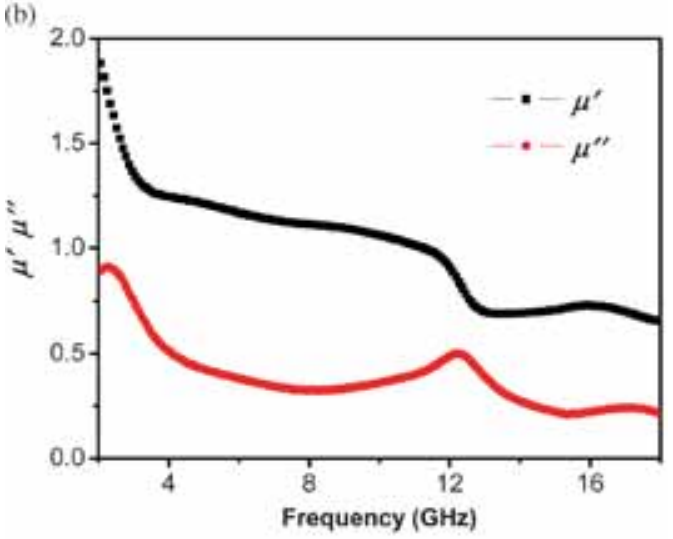

(c)

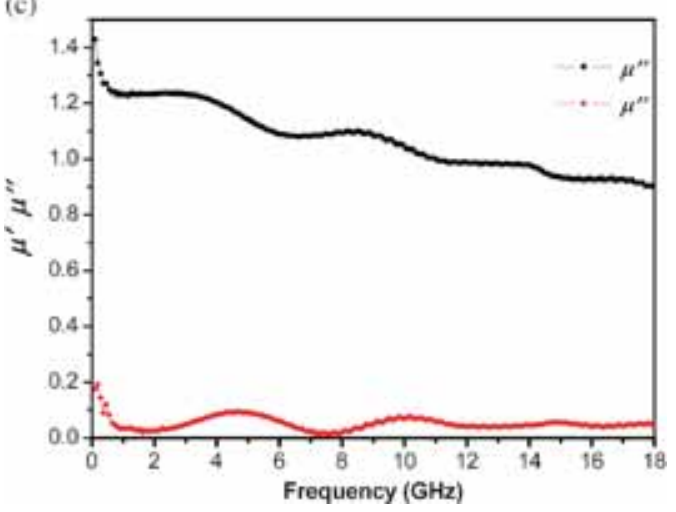

Figure 4. Complex permittivity and permeability of the $\mathrm{Fe}_{0.45}$ $\mathrm{Ni}_{0.55} / \mathrm{CF}$ composites: (a) $\varepsilon^{\prime}$ and $\varepsilon^{\prime \prime}$; (b) $\mu^{\prime}$ and $\mu^{\prime \prime}$; and (c) $\mu^{\prime}$ and $\mu^{\prime \prime}$ of the $\mathrm{Fe}_{0.21} \mathrm{Ni}_{0.69} / \mathrm{CF}$.

show that the optimum thickness of $\mathrm{Fe}_{0.45} \mathrm{Ni}_{0.55} / \mathrm{CF}$ composites is about $3.3 \mathrm{~mm}$, which is thinner than those in other reports. $^{2,11,25-28}$ Figure 5 b shows the lowest reflectivity of $\mathrm{Fe}_{0.21} \mathrm{Ni}_{0.69} / \mathrm{CF}$ composites is $10.2 \mathrm{~dB}$ at $4.8 \mathrm{GHz}$ and the corresponding thickness is $3.4 \mathrm{~mm}$. The microwave absorption of the $\mathrm{Fe}_{0.21} \mathrm{Ni}_{0.69} / \mathrm{CF}$ is similar with $\mathrm{Fe}_{0.45} \mathrm{Ni}_{0.55} / \mathrm{CF}$. because the dielectric loss is caused by CFs. The microwave attenuation of the $\mathrm{Ni}-\mathrm{Fe} / \mathrm{CF}$ composites is mainly caused by dielectric loss in this work. It is well known that CFs are favourable microwave absorbing materials. ${ }^{28,29}$ Therefore $\mathrm{Fe}_{0.45} \mathrm{Ni}_{0.55} / \mathrm{CF}$ composites show excellent microwave absorption at low frequency.
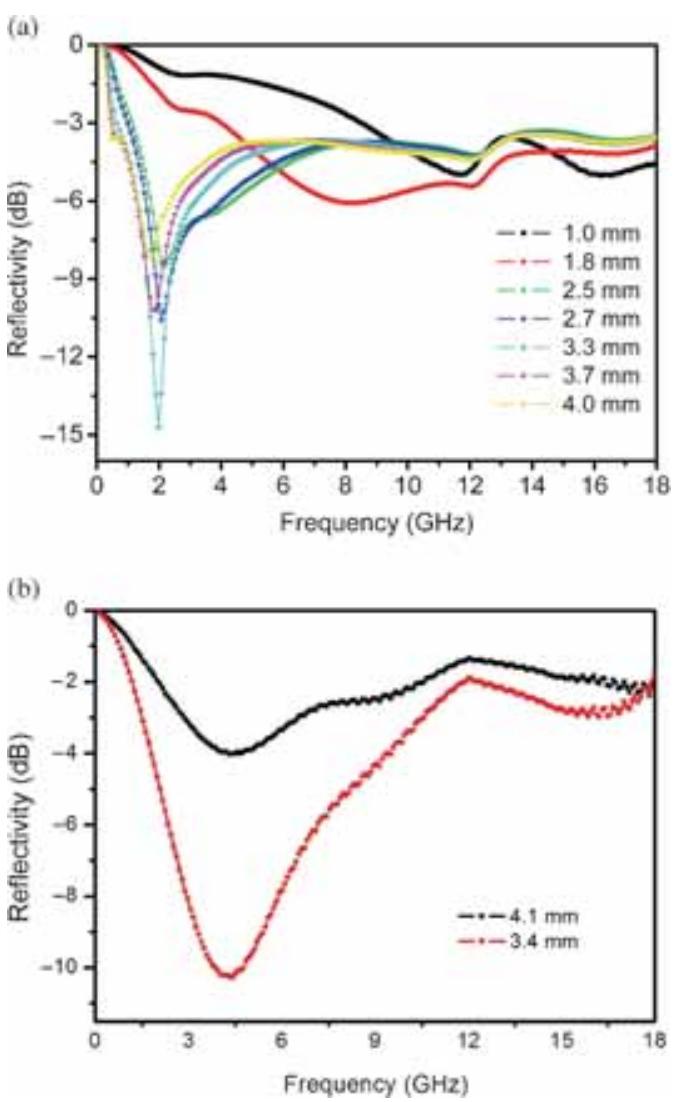

Figure 5. (a) Reflectivity curves of different thicknesses of the (a) $\mathrm{Fe}_{0.45} \mathrm{Ni}_{0.55} / \mathrm{CF}$ composites and (b) $\mathrm{Fe}_{0.21} \mathrm{Ni}_{0.69} / \mathrm{CF}$ composites.

\section{Conclusions}

$\mathrm{Ni}-\mathrm{Fe}$ alloy coatings were successfully prepared on CFs surfaces via a conventional electrodeposition method. The $\mathrm{Ni}-\mathrm{Fe} / \mathrm{CF}$ composites are covered with dense and uniform $\mathrm{Ni}-\mathrm{Fe}$ coatings and the thickness is about $2 \mu \mathrm{m}$. The coercivity $\left(H_{\mathrm{c}}\right)$ and saturation magnetization $\left(H_{\mathrm{s}}\right)$ of the $\mathrm{Fe}_{0.45} \mathrm{Ni}_{0.55} / \mathrm{CF}$ composites are 45.19 Oe and 1213.59 emu $\mathrm{g}^{-1}$. The microwave absorption of the $\mathrm{Ni}-\mathrm{Fe} / \mathrm{CF}$ composites is mainly attributed to both dielectric and magnetic loss. The reflectivity of $\mathrm{Fe}_{0.45} \mathrm{Ni}_{0.55} / \mathrm{CF}$ composites is less than $-5 \mathrm{~dB}$ over the range of $1.1-5.4 \mathrm{GHz}$. The reflectivity of $\mathrm{Fe}_{0.45} \mathrm{Ni}_{0.55} / \mathrm{CF}$ composites is less than $-10 \mathrm{~dB}$ over the range of 1.6-2.1 GHz. The lowest reflectivity of the $\mathrm{Fe}_{0.45} \mathrm{Ni}_{0.55} / \mathrm{CF}$ composites is $-14.7 \mathrm{~dB}$ at $2.0 \mathrm{GHz}$ and the corresponding thickness is $3.3 \mathrm{~mm}$. It is believed that $\mathrm{Ni}-\mathrm{Fe} / \mathrm{CF}$ composites are ideal microwave absorption materials with lighter weight and stronger frequency microwave absorption at low frequency.

\section{References}

1. Wang G Q, Chen X D, Duan Y P and Liu S H 2008 J. Alloys Compd. $\mathbf{4 5 4} 340$

2. Qiang C W, Xu J C, Zhang Z Q, Tian L L, Xiao S T, Liu Y and Xu P 2010 J. Alloys Compd. 50693 
3. Chen Y J, Cao M S, Wang T H and Wan Q 2004 Appl. Phys. Lett. 843367

4. Hatakeyama K and Inui T 1984 IEEE Trans. Magn. 201261

5. Donnet J B, Bansal R C and Wang M J 1990 Carbon fibers (New York: Marcel Dekker) 3rd edn., p 57

6. Zeng J and Xu J C 2010 J. Alloys Compd. 49339

7. Zeng J, Xu J C, Tao P and Hua W 2009 J. Alloys Compd. 487304

8. Zeng J and Xu J C 2009 Mater. Charact. 601068

9. Fan Y Z, Yang H B, Liu X Z, Zhou H Y and Zou G T $2008 \mathrm{~J}$. Alloys Compd. 461490

10. Kang Y Q, Gao M S, Yuan J, Zhang L, Wen B and Fa X Y 2010 J. Alloys Compd. 495259

11. Venkatasetty H V 1970 J. Electrochem. Soc. 117403

12. Romankiw L T, Croll I M and Hatzakis M 1970 IEEE Trans. Magn. 6597

13. Marikkannu K R, Paruthimal Kalaignan $\mathrm{G}$ and Vasudevan $\mathrm{T}$ 2007 J. Alloys Compd. 438332

14. Lodhi Z F, Mol J M C, Hamer W J, Terryn H A and DeWit J H W 2007 Electrochim. Acta 525444

15. Chen Y and Sun I W 2001 Electrochim. Acta 461169

16. Beltowska-Lehman E, Ozga P, Swiatek Z and Lupi C 2002 Surf. Coat. Technol. 444151
17. Gyftou P, Pavlatou E A and Spyrellis N 2007 Appl. Surf. Sci. 2545910

18. Li B S, Lin A, Wu X, Zhang Y M and Gan F X 2008 J. Alloys Compd. 45393

19. Xie G, Wang Z, Cui Z and Shi Y 2005 Carbon 433181

20. Tang Y, Liu L, Wu Y, Zhao H and Hu W 2007 Mater. Lett. 61 1307

21. Aria S and Endo M 2003 Electrochem. Commun. 5797

22. Yang Y, Zhang B, Xu W, Shi Y, Jiang Z and Zhou N 2003 J. Magn. Magn. Mater. 256129

23. Osaka T 1999 Electrochem. Acta 443855

24. Su X H and Qiang C W 2012 Bull. Mater. Sci. 35183

25. Ni S B, Wang X H, Zhou G, Yang F, Wang J M and He D Y 2010 J. Alloys Compd. 489252

26. Homma T, Tamaki A, Nakai H and Osaka T 2003 J. Electroanal. Chem. 559131

27. Liu Q L, Zhang D and Fan T X 2008 Appl. Phys. Lett. 93 013110

28. Feng Y B, Qiu T and Shen C Y 2007 J. Magn. Magn. Mater. 3188

29. Zhao N Q, Zou T C, Shi C S, Li J J and Guo W K 2006 Mater. Sci. Eng. B 127207 